\title{
Utilization of waste spent hydroprocessing catalyst: development of a process for full recovery of deposited metals and alumina support
}

\author{
M. Marafi, M. S. Rana, R. Navvamani \& H. Al-Sheeha \\ Petroleum Refining Department, Kuwait Institute for Scientific Research, \\ $P R \& S C$, Kuwait
}

\begin{abstract}
An emphasis has been placed on investigation spent hydroprocessing catalyst recovery due to environmental regulations which register spent catalysts as hazardous waste materials. Kuwait refinery produces $c a$. 6000 ton/year spent catalysts from the bottom of the barrel (ARDS) processes, which contain valuable metals such as molybdenum, vanadium, nickel or cobalt etc. These catalysts are not viable to regenerate mainly due to the metal deposition. The present study is carried out on industrial spent residue hydroprocessing (ARDS) catalysts that contain high levels of metals. The possibility of recycling total spent catalysts (TSC) was studied by using various steps such as deoiling, drying, grinding, sieving and decoking. In the subsequent steps, the digested spent catalysts were treated with acid-base reactions in order to separate the various components of the spent catalyst. Using various leaching reaction conditions such as acid-base concentration, reaction $\mathrm{pH}$ in aqueous as well as organic mediums were studied. The metals were leached out in the solution while alumina support was recovered as bulk solid in the form of boehmite. The recovered alumina is further treated hydrothermally and recovered as boehmite, samples were characterized by surface area, pore volume, and pore size distribution measurements. Hence, recovery of valuable metals from the spent catalysts is an attractive option for their recycling and utilization. Therefore, TSC recovery is not only important from an environmental point of view but also very vital from an economic viewpoint.

Keywords: spent catalyst, recycling, hazardous waste, residue hydroprocessing, waste utilization.
\end{abstract}




\section{Introduction}

The importance of catalysis to petroleum and fossil fuel processing cannot be overemphasized. No matter what fossil energy sources are being considered worldwide, a clean, sustainable energy future will involve catalysts to improve energy efficiency and to mitigate environmental impacts. Usually, a catalyst performance is measured based on their activity, selectivity and stability that have more impact on overall process economics than does the catalyst cost alone. Depending on the type of feedstock and unit severity, the cycle length of a fixed bed hydroprocessing catalyst is typically between 6 months to 2.5 years. Moreover, in order to maintain the quality of product during the run is compensated by a progressive increase in catalyst bed temperature. When catalyst does not produce required quality product it means that the catalyst is deactivated and required regeneration or replacement. Deactivation is due to three main causes: carbon (coke) laydown, active phase sintering, and metal poisoning. In recent years catalysts play a key role in the refining of petroleum to produce clean fuels and many other valuable products [1, 2]. Therefore, hydroprocessing catalysts has become widely accepted and preferred by the industry due to a number of reasons, such as purification of various petroleum streams, particularly for the upgrading of heavy oils and residues [3]. In the residue hydrotreating process, the catalysts which consist of Mo with promoter $\mathrm{Co}(\mathrm{Ni})$ on alumina support enhance the removal of undesirable impurities such as sulfur, nitrogen, and metals by hydrodesulfurization, hydrodenitrogenation, and hydrodemetallization reactions, respectively [4-6]. Hence catalysts used for this process deactivated rapidly by coke and metal (V and $\mathrm{Ni}$ ) deposits $[6,7]$ and have a short life (6-12 months), which required to dispose of.

Hence, the disposal of spent catalyst poses an unavoidable environmental issue [8] which, essentially requires high capital investment, huge swaths of land and massive efforts. Kuwait, at present is producing around 2.6 million bbl/d (Mbpd) conventional crude oil. It has a refining capacity of about $936,000 \mathrm{bbl} / \mathrm{d}$ in its 3 refineries, which is likely to increase up to $2 \mathrm{Mbpd}$ with the addition of the $4^{\text {th }}$ refinery. Kuwait has total capacity of atmospheric residue (AR) hydrotreating is around 216,000 bpd [7]. Kuwait oil industry has already embarked on plans to expand the exploitation of Kuwait heavy oil reserves, including Lower Fars. Plans are on to construct a new refinery with a capacity estimated at $600,000 \mathrm{bbl} /$ day. The above said processing will lead to large amount of spent catalysts containing high levels of $\mathrm{V}$, together with $\mathrm{Mo}$ and $\mathrm{Ni}$, which will be discarded as solid wastes [8]. Kuwait's current spent catalysts production is $c a$. 6000 tons/yr from the three refineries [9], which is likely to be $c a$. 10,000 tons/yr when $4^{\text {th }}$ refinery will function with heavy crude's residues [7]. The "re-cycle" of catalyst may prevent the waste in vast landfills, which can be effectively used industrial sites to conserve a region's environmental and natural resources $[2,10,11]$. Hence in this work we are fully committed to meet our initiatives toward sustainable development and renewable resources.

The heavy crude oil residue has large amount of metals (mainly $\mathrm{V}$ and $\mathrm{Ni}$ ), which deposit on the catalyst during the reaction and decrease the catalyst's life. 
Since, regeneration and reactivation methodology is not available for metal deactivated catalysts, the disposal of spent catalyst is a major issue. At the same time, refiners are asked for more stringent environmental norms and superior handling of spent catalysts. Many methods being used such as disposal in landfills [12-13], reclamation of metals [9], regeneration/rejuvenation [14-16], reuse $[6,17,18]$, and utilization as raw materials [19]. Most of these methods are not cost effective thus, refiners looks for the cost effective and environmentally safe method. Thus, utilization of spent residue hydroprocessing catalysts as total recovery $(\mathrm{Mo}, \mathrm{Ni}, \mathrm{V}$ and $\mathrm{Al}$ ) of spent catalysts has been considered as an important area. In the current study refinery hydroprocessing spent catalysts are collected from the Kuwait refinery (KNPC) ARDS processing unit. The refinery spent catalyst metals (Ni, Mo and $\mathrm{V}$ ) are recovered as high-quality metal salts at about $95 \%$ purity while high purity alumina is recovered as boehmite.

\section{Experimental}

The recovery of metals and support from spent catalyst obtained from Kuwait refinery hydroprocessing ARDS unit (reactors $3^{\text {rd }}$ and $4^{\text {th }}$ ) is described in Figure 1, by using three different options. Each process has various stages in order to recover metals ( $\mathrm{Mo}, \mathrm{Ni}, \mathrm{V})$ as well as alumina. The spent catalyst was deoiled, decoked, crushed and ground to fine powder (size $<500 \mu \mathrm{m}$ ) using standard equipment and procedures [6], which is a common steps for all the processes.

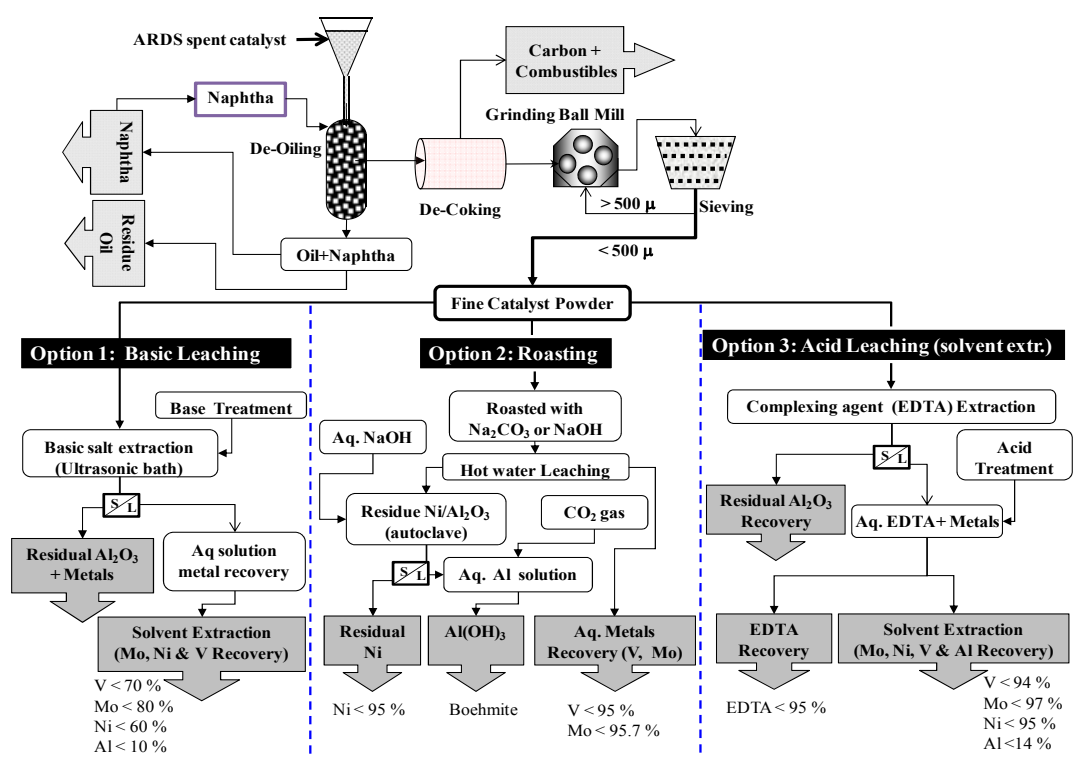

Figure 1: $\quad$ Flow diagram of spent hydroprocessing catalyst recovery processes by using three different options. 
The spent catalysts were examined qualitatively by scanning electron microscope energy dispersive X-ray analysis (SEM-EDX), using TESCAN TSS13MM Vega electron microscope. The physical properties such as surface area, pore volume and pore size distribution of catalysts were measured by BET method using a TriStar 3000 equipment. The separation of metals were carried out in a typical experiment, about 5 grams of the powdered decoked spent catalyst was mixed with the selected acid/base reagent and agitated in an ultrasonic bath for required period of time, temperature and then filtered, except for soda roasting where the spent catalyst was roasted at a range of temperature $\left(500-700^{\circ} \mathrm{C}\right)$. The composition of the catalyst particularly metals such as Mo, $\mathrm{Ni}, \mathrm{V}$ and $\mathrm{Al}$ were determined quantitatively by chemical analysis (ICP, Teledyne-Leeman-High Dispersion ICP) as shown in Table 1. The basic medium (option 1) ammonium salts solution of $\mathrm{NH}_{4} \mathrm{OH},\left(\mathrm{NH}_{4}\right)_{2} \mathrm{CO}_{3}$, and $\left(\mathrm{NH}_{4}\right)_{2} \mathrm{~S}_{2} \mathrm{O}_{8}$ have been used. Soda roasting method (option 2) was carried out with $\mathrm{NaOH}$ and $\mathrm{Na}_{2} \mathrm{CO}_{3}$ in muffle furnace. However, acids leaching (option 3) was studied by using two inorganic acids $\left(\mathrm{H}_{2} \mathrm{SO}_{4}, \mathrm{HNO}_{3}\right)$, and three organic acids (citric, oxalic, acetic and EDTA).

Table 1: $\quad$ Composition of catalyst before and after decoking.

\begin{tabular}{|c|c|c|c|}
\hline \multirow{2}{*}{ Catalyst properties } & \multicolumn{3}{|c|}{ Composition of catalyst, wt $\%$} \\
\cline { 2 - 4 } & Fresh & Spent & Decoked \\
\hline $\mathrm{Mo}$ & 8.0 & 7.46 & 6.73 \\
\hline $\mathrm{Ni}$ & 3.3 & 4.8 & 4.3 \\
\hline $\mathrm{V}$ & - & 9.8 & 10.0 \\
\hline $\mathrm{Carbon}$ & - & 18.1 & $<1$ \\
\hline $\mathrm{Al}_{2} \mathrm{O}_{3}$ & - & 43.5 & - \\
\hline Specific surface $\mathrm{area}_{3}(\mathrm{SSA}), \mathrm{m}^{2} / \mathrm{g}$ & 252 & 102 & 235 \\
\hline Total pore volume (TPV), $\mathrm{ml} / \mathrm{g}$ & 0.58 & 0.05 & 0.51 \\
\hline Average pore diameter (APD), nm & 16.2 & 8.7 & 13.0 \\
\hline
\end{tabular}

Various chemical treatment and precipitation steps were required in order to recover high purity of metals and alumina. The effects of reagent concentration, leaching time and temperature on the extraction of $\mathrm{Mo}, \mathrm{V}, \mathrm{Ni}$ and $\mathrm{Al}$ from the spent catalyst were examined $[17,18]$. High grade alumina can be prepared by using (option 2) caustic digestion, precipitation of boehmite with $\mathrm{CO}_{2}$, and hydrothermal treatment of boehmite.

\section{Results and discussion}

Characterization: The residue hydroprocessing catalysts are subject to change during processing, e.g., carbon and metal deposition, their composition varies depending on feedstock quality and the process conditions. The deposited foreign species are liable to decrease in catalytic activity and the catalyst life particularly with time-on-stream. SEM-EDAX results confirmed that carbon, V, $\mathrm{Ni}, \mathrm{P}$ and Mo (sulfur) are deposited on the surface of the catalyst, which are 
featured by their $\mathrm{K} \alpha$ (in the case of Mo $\mathrm{K}_{L}$, merged with the $\mathrm{S} \mathrm{K} \alpha$ )) X-ray emission lines $(\mathrm{keV})$ as shown in Figure 2. The composition of fresh, spent and de-coked catalyst is shown in Table 1 . The deposited species changes noticeably the specific surface area (SSA) and total pore volume (TPV) of the spent catalyst (Table 1). The decrease in SSA and TPV values indicated that the catalyst is deactivated by pore blockage as well as fouling of the active sites by coke and metal deposits.

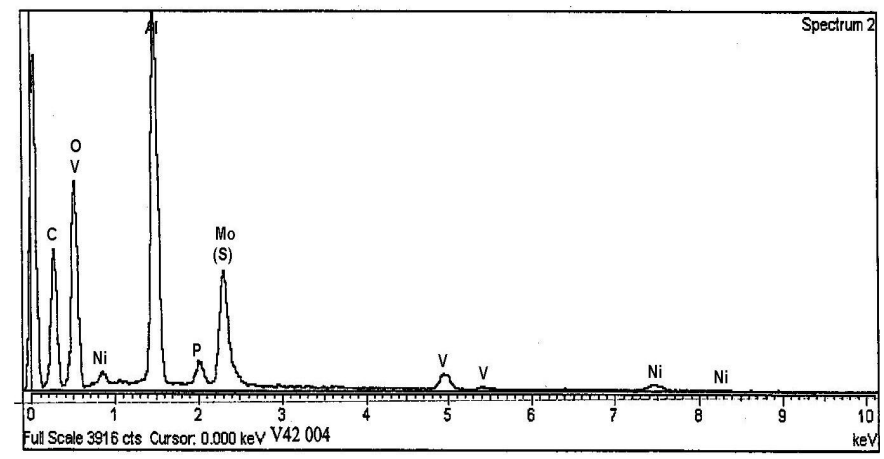

Figure 2: $\quad$ SEM-EDAX analysis of spent hydroprocessing catalyst.

De-oiling and De-coking: The spent catalysts were first washed with naphtha and then extracted with toluene in a soxhlet apparatus to remove the residual oil. The naphtha will be recycled for de-oiling while residual oil can be effectively used for decoking furnace heating. The de-oiled spent catalyst was decoked by combustion in the presence of air under controlled temperature. Since, coke combustion is a highly exothermic reaction, and the catalyst temperature can rise to high levels during the early stages of combustion (de-coking), which may lead to enhance metal-metal interaction or particle size due to sintering of the metals at elevated temperatures [20] and later difficulties to separate metals. The decoking catalyst was subsequently ground in $<500 \mu \mathrm{m}$ size in order to improve leaching efficiencies. During the deoiling soft coke will be removed while hard coke deactivated sites and portion of textural properties can be significantly improved during the decoking process but the metal deactivated sites and pore will not be recovered. The composition of decoked catalyst along with textural properties are shown in Table 1. Therefore, deoiling and decoking (regeneration) processes are the partial recovery of catalyst.

Metal Extraction Studies: This study is to investigate the percentage of metal extraction using different recovery methods such as: acid, base leaching, roasting with sodium salts, digestion with caustic soda in order to monitor the purity of valuable metals and recovery of alumina support from spent catalysts.

Basic leaching of spent catalyst: The basic medium leaching process conditions are established with diluted ammoniac solutions using 1 molar solution at $50^{\circ} \mathrm{C}$ temperature. For a comparison three different basic reagents were tested and metal leaching is shown in Figure 3. By using these basic 
reagents considerable amount of $\mathrm{Mo}$ and $\mathrm{V}$ are recovered while $\mathrm{Ni}$ and $\mathrm{Al}$ showed insignificant reaction with these chemicals. Al extraction percentage was very minimal which indicates that ammonium carbonate is not an active reagent for Al recovery.

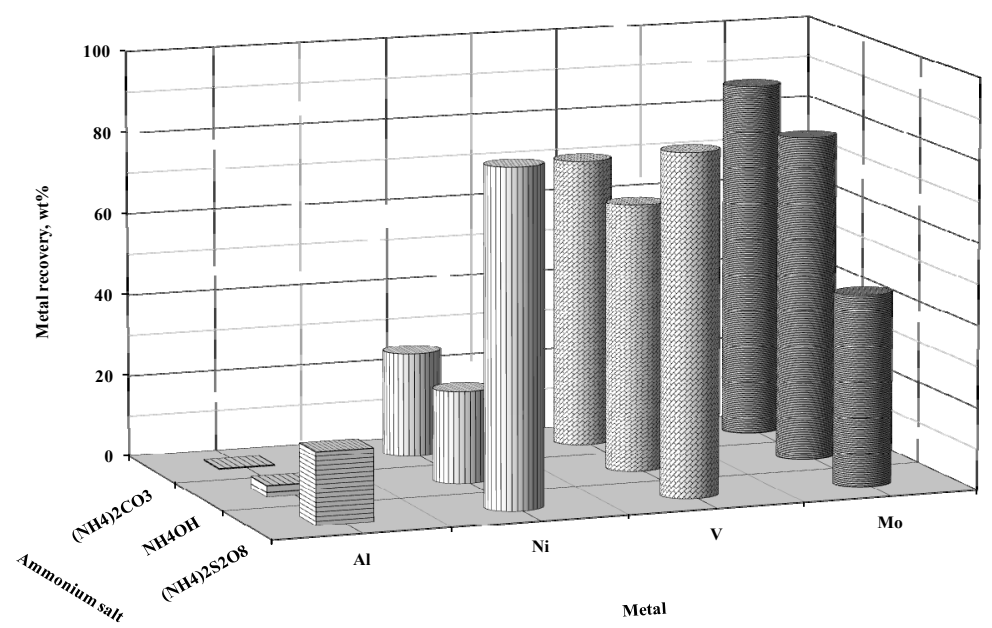

Figure 3: Effect of ammonium salt on the recovery of metals using leaching conditions at $50{ }^{\circ} \mathrm{C}$ and 1 molar solution of salt.

In the case of ammonium per-sulfate amount of $\mathrm{Ni}$ and $\mathrm{Al}$ extracted were relatively higher when compared to the extraction with other two ammonium salts, namely, $\mathrm{NH}_{4} \mathrm{OH}$ and $\left(\mathrm{NH}_{4}\right)_{2} \mathrm{CO}_{3}$. The use of oxidixing $\left(\mathrm{H}_{2} \mathrm{O}_{2}\right)$ and reducing (hydrazine) compound with these agents were also studied [2, 13], which shows an effective removal of metals but the level of extraction remain less than $92 \%$. The different behavior using $\left(\mathrm{NH}_{4}\right)_{2} \mathrm{~S}_{2} \mathrm{O}_{8}$ could be due to its strong oxidizing nature, which promotes the better dissolution of metals. However, ammonium persulfate also forms oxygen free radicals in aqueous solution under mild conditions and promote radical reactions. The ammoniac solutions have possibilities to dissolve these metal cations and separate from the other ions is achieved by various basicity constant or the base ionization constant, i.e., $\left[\mathbf{k}_{\mathbf{b}}=\frac{\left[\mathbf{N H}_{4}^{+}\right]\left[\mathbf{O H}^{-}\right]}{\left[\mathbf{N H}_{3}\right]}=\mathbf{1 . 8} \times \mathbf{1 0}^{-5}\right]$, base dissociation constant, which indicates the relative strength of a base. The separation of each ion depends on the occurrence of reactions that are specific to that ion. It appears, the mild basic agents are capable to partial dissolution of surface deposited metals that are extracted, which leads to low grade alumina residue and the loss of unrecovered metals. The partial recovery (Figure 1) showed in option 1 is less than $80 \%$ and remaining metals will be in the residue alumina.

Leaching with $\mathrm{NaOH}$ under pressure: In order to improve the metal extraction stronger alkaline solution $(\mathrm{NaOH})$ has been carried out in autoclave under nitrogen pressure $(30 \mathrm{bar})$. The temperature used for the digestion of spent 
catalyst with $\mathrm{NaOH}$ in the autoclave was varied from 150 to $250^{\circ} \mathrm{C}$. The concentration of the $\mathrm{NaOH}$ solution was $30 \%$ and the results of these experiments are presented in Figure 4.

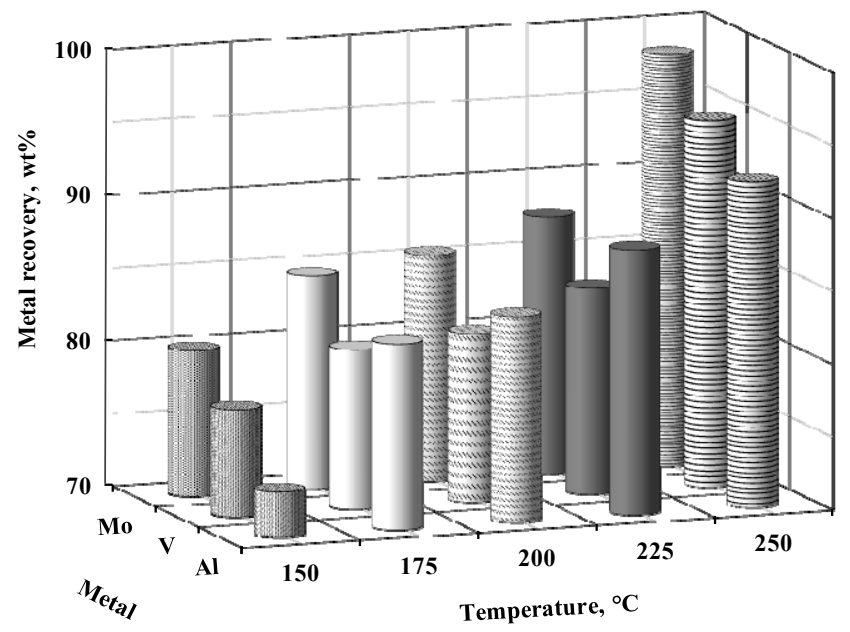

Figure 4: Effect of temperature on the recovery of metals using caustic soda in autoclave (metal extraction using 1:2 ratio of spent to $\mathrm{NaOH}$ ).

The figure results evidently indicate that temperatures around $250^{\circ} \mathrm{C}$ were required in the caustic digestion process to maximize the dissolution and extraction of Mo, $\mathrm{V}$ and Al. The maximum amounts of Mo, V, and Al extracted in the caustic digestion process were $98 \%, 95 \%$, and $92 \%$, respectively. Interestingly, by using $\mathrm{NaOH}$ digestion only $\mathrm{Mo}, \mathrm{V}$ and some extend $\mathrm{Al}$ can be extracted while Ni extraction is almost zero at all the conditions. Marafi and Stanislaus [18] studied an effect of $\mathrm{NaOH}$ concentration on metal extraction and an optimum was obtained at about $22-30 \%$ range. Usually, strongly basic solution like $\mathrm{NaOH}$ at a lower concentration a white gelatinous precipitate of $\mathrm{Al}(\mathrm{OH})_{3}$ was observed, which disappear (dissolve) with increasing hydroxide ion $(\mathrm{NaOH})$ concentration due to the formation of a complex ion $\left[\mathrm{Al}(\mathrm{OH})_{3}(\mathrm{~s})+\right.$ $\left.\mathrm{OH}^{-} \leftrightarrow \mathrm{Al}(\mathrm{OH})_{4}^{-}(\mathrm{aq})\right]$. The separation and detection of each ion depends on the occurrence of reactions that are specific to that ion.

Metal Extraction by Soda Ash Roasting: After decoking the spent catalyst contains metals oxides and alumina support. The samples were dry roasted (eqn. 1) at $550^{\circ} \mathrm{C}$ or $700^{\circ} \mathrm{C}$ in the presence of $\mathrm{NaOH}$ or $\mathrm{Na}_{2} \mathrm{CO}_{3}$ in order to convert $\mathrm{Mo}$ and $\mathrm{V}$ salts (eqn. 2), which is soluble in water and can be easily separated as (eqns. 3-7):

$$
\frac{\mathrm{NiMoV}}{\mathrm{Al}_{2} \mathrm{O}_{3}}+\mathrm{Na}_{2} \mathrm{CO}_{3} \text { or } \mathrm{NaOH} \stackrel{550^{\circ} \mathrm{C} \text { or } 700^{\circ} \mathrm{C}}{\longrightarrow} \text { Roasted spent catalyst }
$$

Roasted catalyst $+\mathrm{H}_{2} \mathrm{O}$

$$
\stackrel{\text { Reflux hot water }}{\longrightarrow} \mathrm{NaVO}_{3} \& \mathrm{Na}_{2} \mathrm{MoO}_{4}(\text { soln })+\mathrm{NiO} / \mathrm{Al}_{2} \mathrm{O}_{3} \text { (residue) }
$$


The chemical equilibria involved in metal oxides is expressed as follows:

$$
\begin{aligned}
\mathrm{MoO}_{3}+\mathrm{Na}_{2} \mathrm{CO}_{3} & \rightarrow \mathrm{NaMoO}_{4}+\mathrm{CO}_{2} \\
\mathrm{~V}_{2} \mathrm{O}_{5}+\mathrm{NaCO}_{3} & \rightarrow 2 \mathrm{NaVO}_{3}+\mathrm{CO}_{2} \\
\mathrm{MoO}_{3}+2 \mathrm{NaOH} & \rightarrow \mathrm{Na}_{2} \mathrm{MoO}_{4}+\mathrm{H}_{2} \mathrm{O} \\
\mathrm{V}_{2} \mathrm{O}_{5}+2 \mathrm{NaOH} & \rightarrow 2 \mathrm{NaVO}_{3}+\mathrm{H}_{2} \mathrm{O} \\
\mathrm{Al}_{2} \mathrm{O}_{3}+2 \mathrm{NaOH} & \rightarrow 2 \mathrm{NaAlO}_{2}+\mathrm{H}_{2} \mathrm{O}
\end{aligned}
$$

The spent catalyst roasted mixture is dissolve with boiling water and solubilised the Mo and $\mathrm{V}$ while $\mathrm{Ni}$ and $\mathrm{Al}_{2} \mathrm{O}_{3}$ separated as insoluble solid. The metals recovery of Mo and $\mathrm{V}$ is shown in Figure 5 . At $550^{\circ} \mathrm{C}$ temperature, the yield of recovery for Mo and $\mathrm{V}$ for $\mathrm{NaOH}$ was more than $97 \%$, while $\mathrm{Na}_{2} \mathrm{CO}_{3}$ was more selective to the Mo and $\mathrm{V}$ removal without reacting the $\mathrm{Ni}$ and $\mathrm{Al}$. With variation of $\mathrm{NaOH}$ concentration vanadium recovery reached the maximum (98\%) with 1:1.5 ratio and then decreased sharply with further increase in the amount of $\mathrm{NaOH}$. However, by increasing sodium carbonate roasting temperature to $700^{\circ} \mathrm{C}$ the Mo and $\mathrm{V}$ recovery reached up to $99 \%$, which made an easy separation for Mo and $\mathrm{V}$. Since, $\mathrm{Ni}$ and $\mathrm{Al}$ do not react with $\mathrm{Na}_{2} \mathrm{CO}_{3}$, it remains as residue. The difference between $\mathrm{NaOH}$ and $\mathrm{Na}_{2} \mathrm{CO}_{3}$ leaching is the recovery of some $\mathrm{Al}$ percent in the solution which make $\mathrm{NaOH}$ roasting process less selective than $\mathrm{Na}_{2} \mathrm{CO}_{3}$. The nickel aluminate residue (eqn. 2) was digested in $\mathrm{NaOH}$, which reacts with alumina and forms sodium aluminate and leave $\mathrm{NiO}$ as an insoluble residue (eqn. 8).

$$
\begin{gathered}
\frac{\mathrm{NiO}}{\mathrm{Al}_{2} \mathrm{O}_{3}} \text { (Residue) }+ \text { aq. } 2 \mathrm{NaOH} \rightarrow \mathrm{NiO}(\text { residue })+\text { aq. } \mathrm{NaAlO}_{2}+\mathrm{H}_{2} \mathrm{O} \\
\text { aq. } \mathrm{NaAlO}_{2}+\mathrm{CO}_{2}(\mathrm{~g})+\mathrm{H}_{2} \mathrm{O} \stackrel{\text { Precipitation }}{\longrightarrow} 2 \mathrm{Al}(\mathrm{OH})_{3}+\mathrm{Na}_{2} \mathrm{CO}_{3} \\
\mathrm{Al}(\mathrm{OH})_{3} \stackrel{\text { Hydrotermal treatment }}{\longrightarrow} \mathrm{AlO}(\mathrm{OH})+\mathrm{H}_{2} \mathrm{O}
\end{gathered}
$$

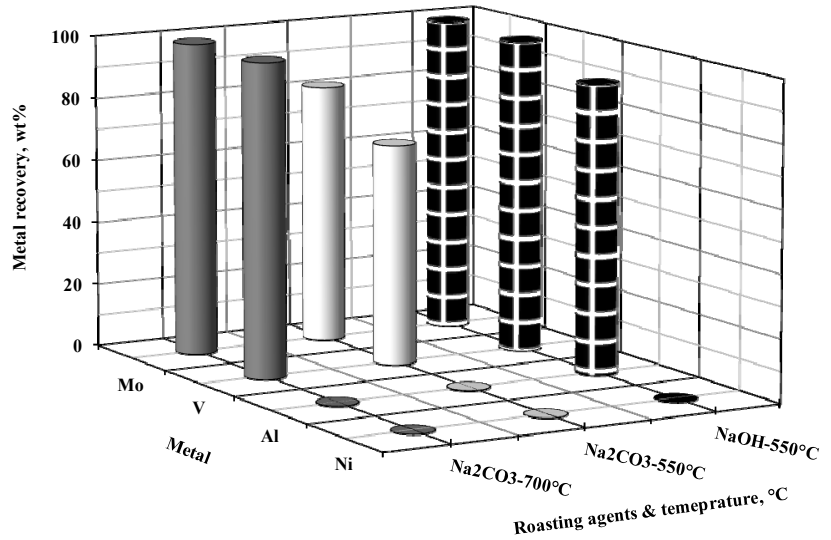

Figure 5: Effect of soda roasting agents and temperature $\left(\mathrm{Na}_{2} \mathrm{CO}_{3}\right)$ on the metal recovery. 
The carbon dioxide gas was bubbled with the sodium aluminate solution in order to precipitate alumina as bayerite $\left[\mathrm{Al}(\mathrm{OH})_{3}\right]$. The aluminum trihydroxide is subject to hydrothermal treatment in a high pressure autoclave in order to modify its textural properties using various hydrothermal conditions such as temperature and digestion time in order to obtained boehmite $[\mathrm{AlO}(\mathrm{OH})]$ phase of alumina. The effect of hydrothermal treatment temperature on the textural properties is shown in Figure 6.

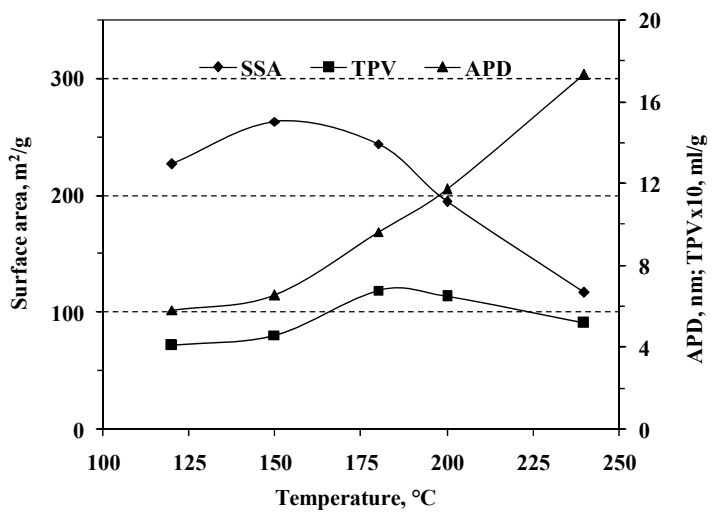

Figure 6: Effect hydrothermal treatment on the boehmite textural properties.

The recovered high purity alumina is highly advantageous for the further use as a support for catalysts. This process for reclamation of special grades alumina and metals $(\mathrm{V}, \mathrm{Mo}, \mathrm{Ni})$ are tangible economic benefits. The process also has technological potential, which is able to recycle total waste material (spent catalyst), and can emerged as an inclusive solution to the hazardous waste.

Acidic leaching of spent catalyst: Acid leaching is one of the most selective method used for spent catalyst separation using two main routes either direct acid leaching under pressure and high temperature or soda roasted spent catalyst followed by acid leaching without pressure and high temperature $[2,21]$. The later method studied as option 3 (Figure 1). In the acid leaching studies, the efficiencies of organic acids such as citric acid, oxalic acid and ethylenediaminetetraacetic acid (EDTA) are compared with that of inorganic acid e.g. sulfuric acid $\left(\mathrm{H}_{2} \mathrm{SO}_{4}\right)$ and nitric acid $\left(\mathrm{HNO}_{3}\right)$. The percentage of metal extraction is shown in Figure 7. The selective leaching usually based on the chemical reaction between the metals and the acid/complexing agents, which produce soluble complex of metals as in eqns (11) and (12).

$$
\begin{gathered}
\mathrm{MO} \text { (roasted spent catalyst) }+\mathrm{H}_{2} \mathrm{X}(\text { complexing agent) } \\
\rightarrow \mathrm{MX} \text { (metal complex) }+\mathrm{H}_{2} \\
k=\frac{[\mathrm{MX}]\left[\mathrm{H}_{2} \mathrm{O}\right]}{[\mathrm{MO}]\left[\mathrm{H}_{2} \mathrm{X}\right]}
\end{gathered}
$$


where $\mathrm{MO}$ refers to metal $(\mathrm{Ni}, \mathrm{Mo}, \mathrm{V}, \mathrm{Al})$ oxides, $k$ is the stability constant, which is high for selectively removed metals. Therefore, the stability of a complex ion is indicated by its formation constant, $k$. A complex ion consists of a central metal ion to which are bonded two, four or six neutral or ionic species called ligands.

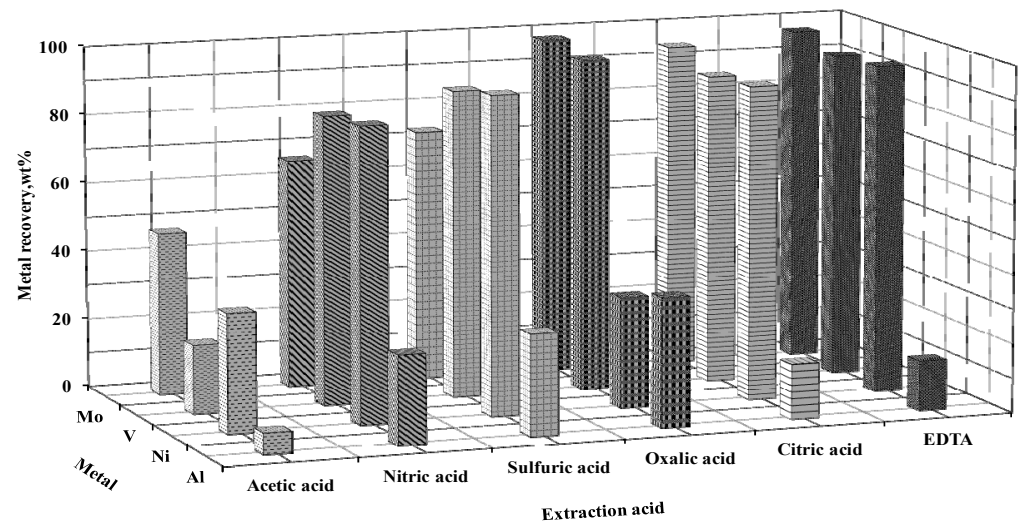

Figure 7: Effect of complexing agent on the metal recovery (at $50^{\circ} \mathrm{C}$ and $6 \mathrm{~h}$ and $10 \%$ concentration of acid/comple).

\section{Oxalic acid $=$ EDTA $>$ Citric acid $>\mathrm{H}_{2} \mathrm{SO}_{4}>\mathrm{HNO}_{3}>>\mathrm{CH}_{3} \mathrm{COOH}$}

The effect of different acids/complexing agents indicated that the organic acids are substantially more significant than the inorganic acids for Mo extraction. Among the organic acids, both oxalic acid and EDTA were slightly more effective than citric acid for Mo and V extraction. Extraction of Mo and V at about $97 \%$ was achieved with both oxalic acid and EDTA, whereas, with citric acid, the recovery was around $92 \%$. The effectiveness (Mo and V extraction) of the five acids used in this study can be ranked in the following order.

Oxalic acid was highly effective for Mo and V extraction, but showed very poor activity for Ni extraction, which follow the order EDTA $>$ Citric acid = $\mathrm{H}_{2} \mathrm{SO}_{4}>\mathrm{HNO}_{3}>\mathrm{CH}_{3} \mathrm{COOH}>$ Oxalic acid. Aluminum extraction, both organic and inorganic acids showed poor activity. Using acid leaching the recovery of $\mathrm{Al}$ is obtained only $37 \%, 29 \%$ and $25 \%$ with oxalic, sulphuric and nitric acids, respectively. The effect of different organic acids can be understood based on their $\mathrm{K}_{\mathrm{a}}$ (acid dissociation constant) values, which is a good indicator for the degree of ionization. The used organic acid has monoprotic (acidic acid, $\mathrm{K}_{\mathrm{a}}=1.8 \times 10^{-5}$ ), diprotic (oxalic acid, $K_{\mathrm{a}}=5.9 \times 10^{-2}$ and $6.4 \times 10^{-5}$ ), triprotic (citric acid, $\mathrm{K}_{\mathrm{a}}=8.4 \times 10^{-4}, 1.8 \times 10^{-5}, 4.0 \times 10^{-6}$ ) and tetraprotic acid (EDTA, $\mathrm{Ka}=1.0 \times 10^{-2}$, $\left.2.2 \times 10^{-3}, 6.9 \times 10^{-7}, 5.5 \times 10^{-11}\right)$. Lower the Ka value greater is the acid strength while smaller is the conjugated base produced by the acid. Therefore, values refer to an ionic strength of the solution that is required for an interaction of particular metal cations $\left[\mathrm{M}^{\mathrm{n}+}+\mathrm{EDTA}^{4-} \leftrightarrow[\mathrm{M}(\mathrm{EDTA})]^{(\mathrm{n}-4)+}\right]$. The presence of more than one metal ion has different formation constants (e.g., metal-EDTA complexes). In the case of EDTA, a pair of unshared electrons capable of 
complexing with a metal ion is contained on each of 2 nitrogens and $4-\mathrm{COOH}$ groups (six complexing groups). The amino nitrogens are more basic and are protonated $\left(-\mathrm{NH}_{3}^{+}\right)$more strongly than carboxylate groups, which bind to the metal atoms by losing their protons. The results of the metal extraction studies with different acids showed that EDTA was very effective in the extraction of the three major metals, namely Mo, V and Ni present in the spent catalyst. Citric acid was moderately active for the extraction of all three metals with extraction percentages in the range from 88 to $93 \%$. The inorganic acids were relatively less effective than the organic acids in the extraction of Mo and V, but they were equally good for Ni extraction. Since large amount of organic acids (oxalic and citric) is required in order to recover metals, which may not be cost effective way. However, EDTA can be recovered by the $\mathrm{H}_{2} \mathrm{SO}_{4}$ treatment thus, this process can be efficiently used in the commercial applicability of the metal recovery of spent catalyst. The dechelation process takes place by using $\mathrm{H}_{2} \mathrm{SO}_{4}$ $(\mathrm{pH}=1)$ to break the metal- complex and EDTA which was recovered as $\mathrm{H}_{4}$ EDTA in the solid form and aqueous solution contains metals in leached liquor (Mo, V, Ni and Al). The EDTA recovery is about $95 \%$, which make this process highly economically viable.

\section{Conclusions}

- The recovery of boehmite or $\gamma$-alumina after recovering the metals (V, Mo, $\mathrm{Ni}$ ) is an economic process that proves a method of total recycling of the spent catalyst waste material, and achieved a complete solution to the environmental problem of the hazardous spent catalyst waste management.

- The ammoniacal solution (basic) leaching showed poor separation of metal and produce impure alumina.

- Soda roasting method revealed that $\mathrm{Na}_{2} \mathrm{CO}_{3}$ is more effective than $\mathrm{NaOH}$ leaching, as molybdenum and vanadium are selectively extracted over nickel and aluminum. The residue can be further separated as nickel and bulk of solid alumina with high purity.

- The inorganic acids were relatively less effective than the organic acids for the extraction of Mo and V, but they were equally good for Ni extraction. Oxalic acid exhibited the highest leaching efficiency towards Mo and $\mathrm{V}$ metals but very poor recovery for Ni. EDTA is very effective for Mo, $\mathrm{V}$ and Ni recoveries.

\section{Acknowledgement}

The authors wish to thank the Kuwait Foundation for the Advancement of Science (KFAS) for their financial support (project: PF037C). 


\section{References}

[1] Stanislaus, A. Marafi, A. and Rana, M.S. Recent advances in the science and technology of ULSD production, Catalysis Today, 153, 1-68, 2010.

[2] Marafi, M., Stanislaus, A. and Furimsky, E., Handbook of Spent Hydroprocessing Catalysts: Regeneration, Rejuvenation, Reclamation, Environment and Safety, Elsevier, 2010.

[3] Rana, M. S. Samano, V. Ancheyta, J., Diaz, J.A.I. A review of recent advances on process technologies for upgrading of heavy oils and residua, Fuel, 86, 1216-1231, 2007.

[4] Furimsky, E., Catalysts for upgrading heavy petroleum feeds, $1^{\text {st }}$ Ed. 169, Elsevier Science, 2007.

[5] Absi-Halabi, M., Stanislaus, A. and Trimm, D.L. Coke formation on catalysts during the hydroprocessing of heavy oils. Appl. Cat., 72, 193-215, 1991.

[6] Marafi, M. and Stanislaus, A. Studies on recycling and utilization of spent catalysts: Preparation of active HDM catalyst compositions from spent residue hydroprocessing catalysts, App. Catal. B: Env. 71, 199-206, 2007.

[7] Marafi, M. Personal communication in KNPC refinery.

[8] Rapaport, D. Spent hydroprocessing catalysts listed as hazardous wastes. Hydrocarbon Process. 79, 11-22, 2000.

[9] Marafi, M. and Stanislaus, A. Options and processes for spent catalyst handling and utilization, J. Hazardous Materials, 101, 123-132, 2003.

[10] Chen, Y.; Feng, Q.; Shao, Y.; Zhang, G.; Ou, L.; Lu, Y. Research on the recycling of valuable metals in spent $\mathrm{Al}_{2} \mathrm{O}_{3}$-based catalyst. Miner. Eng. 19, 94-97, 2006.

[11] U.S. EPA, Test Methods for Evaluating Solid Waste, Physical/Chemical Methods, 1996, http://www.epa.gov/epaoswer/hazwaste/test/main.htm.

[12] Marafi, M. and Stanislaus, A., Spent catalyst waste management: A review: Part I-Developments in hydroprocessing catalyst waste reduction and use, Resources, Conservation and Recycling, 52(6), 859-873, 2008 a.

[13] Marafi, M. and Stanislaus, A. Spent catalyst waste management: A review: Part II-Advances in metal recovery and sae disposal method, Resources, Conservation and Recycling, 53, 1-26, $2008 \mathrm{~b}$.

[14] Trimm, The regeneration or disposal of deactivated heterogeneous catalysts. Appl. Catal., A 212, 153-160, 2001.

[15] Dufresne, P., Hydroprocessing catalysts regeneration and recycling. Applied Catalysis A: Gen. 322, 67-75, 2007.

[16] Furimsky, E. Spent refinery catalysts: Environment safety and utilization. Catalysis Today 30, 223-286, 1996.

[17] Marafi, M. and Stanislaus, A. Waste catalyst utilization: extraction of valuable metals from spent hydroprocessing catalysts by ultrasonic-assisted leaching with acids, Ind. Eng. Chem. Res., 50, 9495-9501, 2011.

[18] Marafi, M. and Stanislaus, A. Alumina from reprocessing of spent hydroprocessing catalyst, Catalysis Today, 178, 117-123, 2011.

[19] Marafi, M., Process for recovering boehnite and $\gamma-\mathrm{Al}_{2} \mathrm{O}_{3}$ from spent hydroprocessing catalyst, US Patent Application 2012/0051988A1. 
[20] Twigg, M.V., Catalyst Handbook, $2^{\text {nd }}$ Ed. Wolfe Publ. Co., London, 1989.

[21] Zeng, L. and Cheng, C.Y. A literature review of the recovery of molybdenum and vanadium from spent hydrodesulfurization catalyst. Part I: Metallurgical process, Hydrometallurgy, 98, 1-9, 2009. 